\title{
Relationship between IL-10 gene -819C/T polymorphism and the risk of inflammatory bowel disease: a meta-analysis.
}

\author{
Haien $\mathrm{Wu}^{1,2}$, JingJing $\mathrm{Guo}^{3}$,Yajun $\mathrm{He}^{4}$, Hekun Yin ${ }^{2}$, Jianchang Shu ${ }^{1}$
}

1. Department of Gastroenterology, Guangzhou Red Cross Hospital, Medical College, Jinan University, Guangzhou 510220,China;

2. Department of Gastroenterology, Jiangmen Central Hospital, Jiangmen 529030,China;

3. Department of Nephrology, Jiangmen Central Hospital, Jiangmen 529030,China;

4. Center of Clinical Laboratory Medicine, Guangzhou Red Cross Hospital, Medical College, Jinan University, Guangzhou 510220,China.

\begin{abstract}
Background: The -819C/T polymorphism in interleukin 10 (IL-10) gene has been reported to be associated with inflammatory bowel disease (IBD), but the previous results are conflicting.

Materials and methods: The present study aimed at investigating the association between this polymorphism and risk of IBD using a meta-analysis.PubMed, Web of Science,EMBASE,google scholar and China National Knowledge Infrastructure (CNKI) databases were systematically searched to identify relevant publications from their inception to April 2016.Pooled odds ratio (OR) with 95\% confidence interval (CI) was calculated using fixed- or random-effects models.

Results: A total of 7 case-control studies containing 1890 patients and 2929 controls were enrolled into this meta-analysis, and our results showed no association between IL-10 gene $-819 \mathrm{C} / \mathrm{T}$ polymorphism and IBD risk(TT vs. CC:OR=0.81,95\%CI 0.641.04;CT vs. CC:OR=0.92,95\%CI 0.81-1.05; Dominant model: OR=0.90,95\%CI 0.80-1.02; Recessive model: OR=0.84,95\%CI 0.66-1.06). In a subgroup analysis by nationality, the $-819 \mathrm{C} / \mathrm{T}$ polymorphism was not associated with IBD in both Asians and Caucasians. In the subgroup analysis stratified by IBD type, significant association was found in Crohn's disease(CD)(CT vs. CC:OR $=0.68,95 \%$ CI $0.48-0.97)$.
\end{abstract}

Conclusion: In summary, the present meta-analysis suggests that the IL-10 gene -819C/T polymorphism may be associated with CD risk.

Keywords: Interleukin 10, -819C/T polymorphism, inflammatory bowel disease

DOI: http://dx.doi.org/10.4314/ahs.v16i3.30

Cite as: Wu H, Guo JJ,He Y, Yin H, Shu JC. Relationship between IL-10 gene-819C/T polymorphism and the risk of inflammatory bowel disease: a meta-analysis. Afri Health Sci 2016;16(3): 866-872. DOI: http:// dx.doi.org/10.4314/abs.v16i3.30

\section{Introduction}

A recent report revealed that the incidence and prevalence of inflammatory bowel disease (IBD), clinically classified into ulcerative colitis (UC) and Crohn's disease (CD), is increasing with time and in different regions around the world, indicating its emergence as a global disease $^{1}$. In Europe the highest annual incidence of CD is $12.7 / 100000$ and $\mathrm{UC}$ is $24.3 / 100000$. In Asia and in the

\section{Corresponding author:}

Jianchang Shu,

Department of gastroenterology,

Affiliated Guangzhou

Red Cross Hospital of Jinan University,

Guangzhou 510220, China.

E-mail:shujianchang@163.com

African Health Sciences Vol 16 Issue 3, September 2016
Middle East both rates are much lower (CD: 5.0/100000 and UC: $6.3 / 100000)^{1}$. Little is known about the underlying pathogenesis of IBD. Several factors such as genetic, environmental, immune and infectious factors and their interaction contribute to the onset of $\mathrm{IBD}^{2}$. Many genes may be associated with the susceptibility to IBD, including migration inhibitory factor and cytotoxic T lymphocyte associated antigen-4 $4^{3,4}$.

Interleukin 10 (IL-10), primarily produced by monocytes and lymphocytes, is a multifunctional cytokine that functions in immune regulation and inflammation ${ }^{5}$. A previous study that during IBD,IL-10 can down-regulate interleukin-1b and TNFa mRNA levels in peripheral monocytes and mononuclear cells of intestinal lamina propria in $\mathrm{IBD}^{6}$. Additionally, a role of IL-10 in IBD pathogenesis was initially suggested by the animal experiment that IL- 
10-deficient mice develop enterocolitis when they are not kept in a germ-free environment ${ }^{7}$. In severe CD and UC patients, a defective IL-10 production was identified ${ }^{8}$.

The IL-10 gene maps to chromosome 1q31-32.A C-to-T single base pair substitution was identified in the promoter region of the IL-10 gene - 819 base pairs upstream of the transcriptional start site.This single base pair substitution has been named $-819 \mathrm{C} / \mathrm{T}^{9}$. The most commonly studied genetic variants in the IL-10 gene are 3 promoter polymorphisms:-592C/A,-819C/T and $-1082 \mathrm{G} / \mathrm{A}^{10}$. Recent meta analysis provided evidence for an association between IL-10 gene 1082A/G polymorphism and susceptibility of IBD $^{11}$.

In addition to the $1082 \mathrm{~A} / \mathrm{G}$ polymorphism having effects on IBD susceptibility, there have also been reports that the IL-10 gene $-819 \mathrm{C} / \mathrm{T}$ polymorphism is associated with IBD. However, these conclusions are inconclusive due to insufficient power, small effect and false-positive results of this polymorphism on IBD susceptibility. Meta-analysis is a statistical method that can be used to overcome the limitations of individual studies ${ }^{12}$. Therefore, we performed a meta-analysis of all eligible studies to assess the association of the IL-10 gene $-819 \mathrm{C} / \mathrm{T}$ polymorphism and IBD risk.

\section{Methods}

\section{Literature search strategy}

Literature databases including PubMed, Web of Science,EMBASE,google scholar and China National Knowledge Infrastructure (CNKI) databases were searched. The search strategy was designed to identify all possible studies that included the following key words: "IL-10 gene", "inflammatory bowel disease/IBD", "-819C/T", "single nucleotide polymorphism" and "genetic polymorphism". All related studies published in English language were included. The reference lists of the retrieved articles were manually searched. If more than one publication were published using the same data, only the study with the largest sample size was included in future analysis.

\section{Study selection}

The studies included in the meta-analysis had to meet all of the following inclusion criteria: i) case-control studies that addressed IBD cases and healthy controls; ii) studies on the association of the IL-10 gene $-819 \mathrm{C} / \mathrm{T}$ poly- morphism and susceptibility to IBD and iii) studies that included sufficient genotypic data for extraction. Interim analyses, overlapping study populations, animal studies and comparisons of laboratory methods were excluded.

\section{Data extraction}

Two investigators retrieved data from the literature based on the same inclusion standards and then performed a cross-check. Any disagreement was resolved by discussion or by a third investigator. The following information was recorded for each study: name of the first author, year of publication, country of study, nationality of the subjects, number of patients and controls, polymorphisms of gene and evidence of Hardy- Weinberg equilibrium (HWE).

\section{Statistical analysis}

The Hardy-Weinberg equilibrium of the control group was calculated by chi-squared test. $\mathrm{P}<0.05$ was considered statistically significant. The association between the IL-10 gene -819C/T polymorphism and IBD was estimated by calculating pooled $\mathrm{OR}$ and $95 \% \mathrm{CI}$ under a co dominant (T'T vs. CC;CT vs. CC), a dominant(T'T+CT vs. CC), or a recessive model('T' vs. CT $+\mathrm{CC}$ ). The statistical heterogeneity among studies was assessed with $\mathrm{I} 2$ statistics. ${ }^{12}$ values of 25,50 and $75 \%$ were defined as low, moderate and high estimates, respectively. When I2 > 50\% indicated heterogeneity across studies, the random effects model was used for meta-analysis; otherwise ,the fixed effects model was used. When study groups are homogeneous, the two models are similar, but if this is not the case the random effects model usually provides wider CIs than the fixed effects model. The random effects model is best used in the between-study heterogeneity ${ }^{12}$.

Subgroup analysis by ethnicity and disease type were performed to examine the source of heterogeneity. Sensitivity analysis was performed by comparison of random effect model values compared to the fixed effect values. The funnel plot asymmetry was assessed by Begg's test and Egger regression asymmetry test to estimate the potential publication bias $^{13}$.Data analysis was performed using STATA version 12 (StataCorp LP,College Station, Texas, USA). The power of each study was computed as the probability of detecting an association between the $-819 \mathrm{C} /$ Tpolymorphism and IBD using a significance level of 0.05 , assuming an OR of 1.5 (small effect size). Power analysis was performed using the statistical program PS: Power and Sample Size Calculation (http://biostat.mc.vanderbilt.edu/wiki/Main/PowerSampleSize) ${ }^{14}$.

African Health Sciences Vol 16 Issue 3, September 2016 


\section{Results}

\section{Study characteristics}

As shown in Figure 1,8597 491 studies exploring the relationship between IL-10 gene $-819 \mathrm{C} / \mathrm{T}$ polymorphism and IBD susceptibility were identified. Finally, a total of 7 case-control studies met the preset inclusion criteria, in which 1890 cases and 2929 controls were included for the pooled analysis ${ }^{15-21}$. The characteristics of the studies are summarized in Table 1. All the studies were published in English. The source of controls was mainly based on healthy populations. The HWE test was performed on genotype distribution of the controls were consistent with HWE. Six of 7 studies were conducted on Caucasian subjects and one study was conducted on Asian subjects. In this meta-analysis, there were six CD studies and three UC studies investigating the correlation with the IL-10 gene $-819 \mathrm{C} / \mathrm{T}$ polymorphism. The statistical power of these 7 studies ranged from $20.4 \%$ to $78.5 \%$. None of the included studies had a sufficient statistical power exceeding $80 \%$.

Table 1. Characteristics of the included studies for meta-analysis

\begin{tabular}{|c|c|c|c|c|c|c|c|c|c|c|c|}
\hline \multirow[t]{2}{*}{ Study included } & \multirow[t]{2}{*}{ Year } & \multirow[t]{2}{*}{ Area } & \multirow[t]{2}{*}{ Race } & \multirow[t]{2}{*}{$\begin{array}{l}\text { Cases/ } \\
\text { Controls }\end{array}$} & $\begin{array}{ll}\text { Genotypes } & \text { for } \\
\text { cases(IBD) } & \end{array}$ & $\begin{array}{l}\text { Genotypes for } \\
\text { cases(UC) }\end{array}$ & $\begin{array}{l}\text { Genotypes } \\
\text { cases(CD) }\end{array}$ & \multicolumn{2}{|c|}{$\begin{array}{l}\text { Genotypes } \\
\text { controls }\end{array}$} & \multirow[t]{2}{*}{ for } & \multirow[t]{2}{*}{$\begin{array}{l}\text { HWE } \\
\text { test }\end{array}$} \\
\hline & & & & & $\begin{array}{lll}\text { CC } & \text { CT } & \text { TT }\end{array}$ & $\begin{array}{llll}\text { CC } & \text { CT } & \text { TT }\end{array}$ & $\begin{array}{llll}\text { CC } & \text { CT } & \text { TT }\end{array}$ & $\mathrm{CC}$ & CT TT & & \\
\hline Fernandez et al. & 2005 & Spain & Caucasian & $470 / 520$ & $278 \quad 15933$ & $15270 \quad 20$ & $\begin{array}{lll}12689 & 13\end{array}$ & 293 & 18542 & & 0.10 \\
\hline Tedde et al. & 2008 & Italy & Caucasian & $203 / 391$ & $127 \quad 63 \quad 13$ & $\begin{array}{ll}127 \quad 63 \quad 13\end{array}$ & l & 229 & 13824 & & 0.60 \\
\hline Sanchez et al. & 2009 & Canada & Caucasian & $117 / 94$ & $\begin{array}{lll}64 & 39 & 14\end{array}$ & / & $\begin{array}{lll}64 & 39 & 14\end{array}$ & 50 & $37 \quad 7$ & & 0.27 \\
\hline Amre et al. & 2009 & Canada & Caucasian & $270 / 336$ & $158 \quad 94 \quad 15$ & / & $15894 \quad 15$ & 172 & 13228 & & 0.71 \\
\hline Andersen et al. & 2010 & Denmark & Caucasian & $336 / 779$ & 2161119 & / & 2161119 & 483 & 25937 & & 0.76 \\
\hline Ahirwar et al. & 2011 & India & Asian & $153 / 207$ & $\begin{array}{lll}42 & 83 & 28\end{array}$ & $\begin{array}{lll}31 & 67 & 19\end{array}$ & $11 \quad 169$ & 61 & 10640 & & 0.62 \\
\hline Wang et al. & 2011 & $\begin{array}{l}\text { New } \\
\text { Zealand }\end{array}$ & Caucasian & $341 / 602$ & 20612114 & l & $206121 \quad 14$ & 365 & 20532 & & 0.65 \\
\hline
\end{tabular}

HWE, Hardy-Weinberg equilibrium
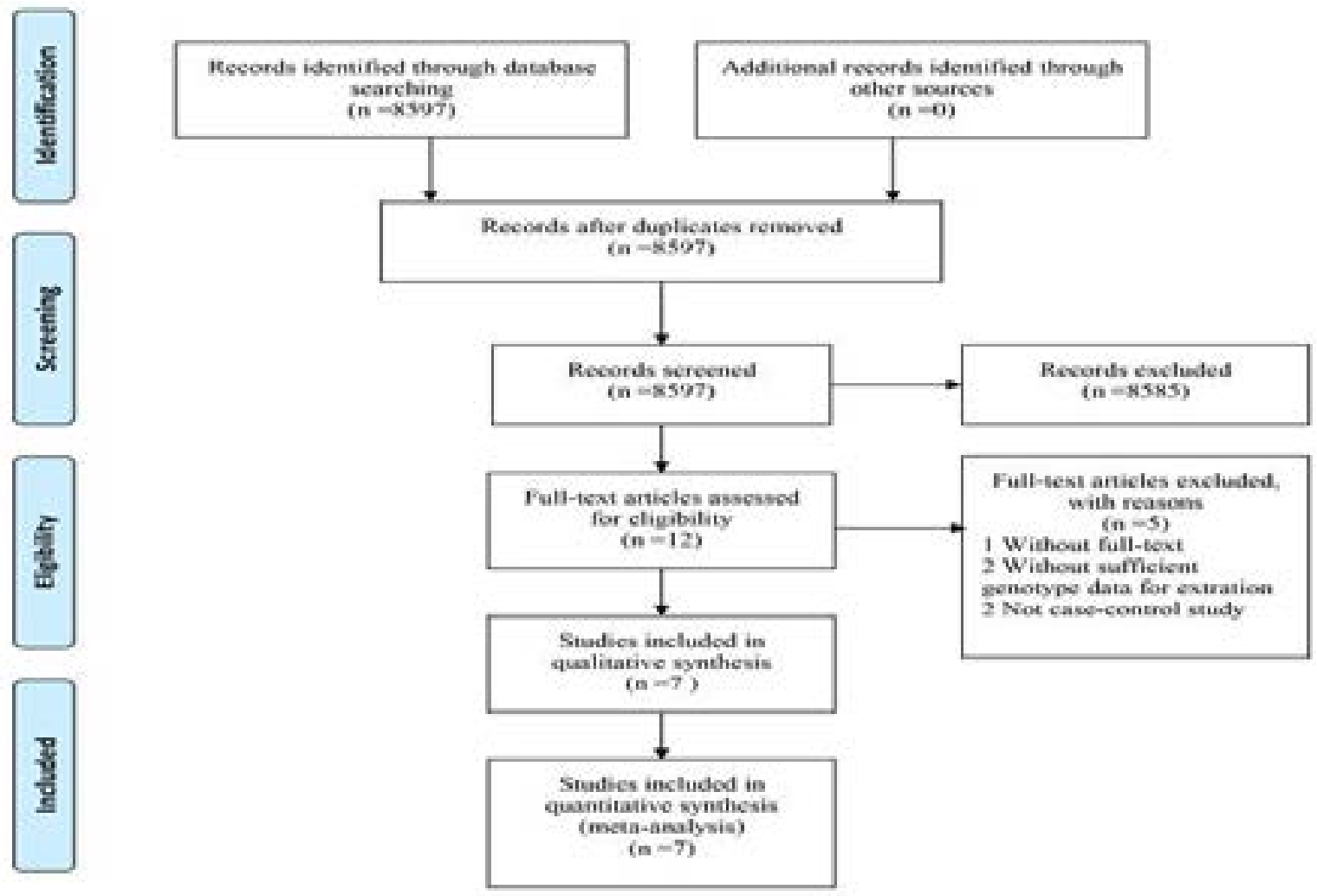

Figure 1. The flow chart of the included studies in the meta-analysis. 
Overall meta-analysis and further subgroup analysis Table 2 lists the main results of the pooled analysis and Figure 2 shows the association of the IL- 10 gene -819C/ $\mathrm{T}$ polymorphism with IBD risk in the form of forest plots. In the overall analysis, no significant association was found between the risk of IBD and the IL-10 gene $-819 \mathrm{C} / \mathrm{T}$ polymorphism(T'T vs. CC:OR $=0.81,95 \% \mathrm{CI}$ 0.64-1.04;CT vs. CC:OR=0.92,95\%CI 0.81-1.05; Domi- nant model:OR $=0.90,95 \%$ CI $0.80-1.02$; Recessive model: $\mathrm{OR}=0.84,95 \% \mathrm{CI} 0.66-1.06)$. To assess the potential effect of the confounding factors on the overall results, we next performed subgroup analyses. When the results were stratified according to ethnicity, the $-819 \mathrm{C} / \mathrm{T}$ polymorphism was not associated with IBD in either Asians or Caucasians (Table 2).In the subgroup analysis stratified by IBD type, a significant association was found in $\mathrm{CD}(\mathrm{CT}$ vs. $\mathrm{CC}: \mathrm{OR}=0.68,95 \% \mathrm{CI}$ 0.48-0.97).

Table 2. Summary of different comparative results.

\begin{tabular}{|c|c|c|c|c|c|c|}
\hline & $\mathbf{N}$ & Cases/controls & TT vs. CC & CT vs. CC & Dominant model & Recessive model \\
\hline Variables & & & OR(95\%CI) $I^{2}$ & OR(95\%CI) $I^{2}$ & OR(95\%CI) $I^{2}$ & $\begin{array}{ll}\text { OR(95\%CI) } & I^{2}\end{array}$ \\
\hline $\begin{array}{l}\text { Total } \\
\text { Ethnicity }\end{array}$ & 7 & $1890 / 2929$ & $0.81(0.64-1.04) \quad 0.0 \%$ & $0.92(0.81-1.05) 0.0 \%$ & $0.90(0.80-1.02) \quad 0.0 \%$ & $0.84(0.66-1.06) \quad 0.0 \%$ \\
\hline Asian & 1 & $153 / 207$ & $1.02(0.55-1.89) /$ & $1.14(0.70-1.85) /$ & $1.10(0.69-1.76) /$ & $0.94(0.55-1.60) /$ \\
\hline $\begin{array}{l}\text { Caucasian } \\
\text { Disease type }\end{array}$ & 6 & $1737 / 2722$ & $0.78(0.60-1.02) \quad 0.0 \%$ & $0.91(0.80-1.04) \quad 0.0 \%$ & $0.89(0.79-1.01) \quad 0.0 \%$ & $0.82(0.63-1.06) \quad 0.0 \%$ \\
\hline $\mathrm{UC}$ & 3 & $562 / 1118$ & $0.86(0.59-1.24) \quad 0.0 \%$ & $0.84(0.67-1.05) \quad 28.4 \%$ & $0.90(0.74-1.11) 11.1 \%$ & $0.95(0.67-1.35) \quad 0.0 \%$ \\
\hline $\mathrm{CD}$ & 6 & $1325 / 2538$ & $0.75(0.56-1.02) \quad 0.0 \%$ & 0.68(0.48-0.97) $82.4 \%$ & $0.78(0.55-1.10) \quad 78.9 \%$ & $0.79(0.59-1.05) \quad 12.3 \%$ \\
\hline
\end{tabular}

$\mathrm{N}$ : number; $I^{2}$ : Inconsistency index; CI: confidence interval; OR: odds ratio. When $\mathrm{I}^{2}>50 \%$, the random effects model was used,or else the fixed effects model was used.

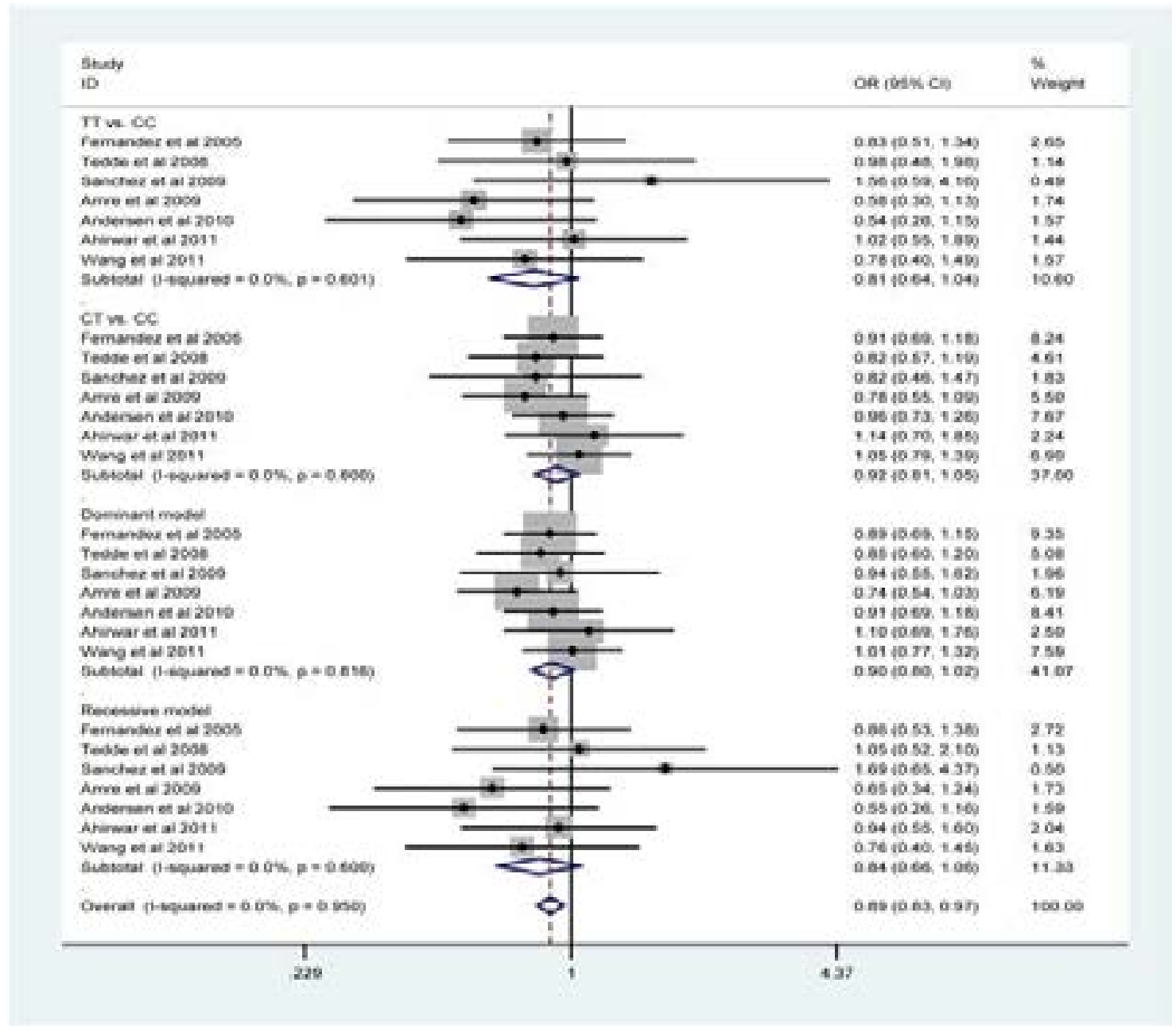

Figure 2. Forest plots for the association of $-819 \mathrm{C} / \mathrm{T}$ polymorphism in IL-10 gene with risk of IBD. For each study, the estimates of OR and its $95 \%$ CI were plotted with a box and a horizontal line. The symbol filled diamond indicates pooled OR and its $95 \% \mathrm{CI}$. 
Sensitivity analysis and publication bias

Sensitivity analysis was performed to evaluate the stability of the results through random effect model values compared to the fixed effect. By using random effect model, the result was not altered, indicating the result of metaanalysis was statistically significant. The Begg's test and Egger regression asymmetry test were used to assess the publication bias of literatures. There was no evidence of publication bias in our study (Figure 3 and Figure 4).

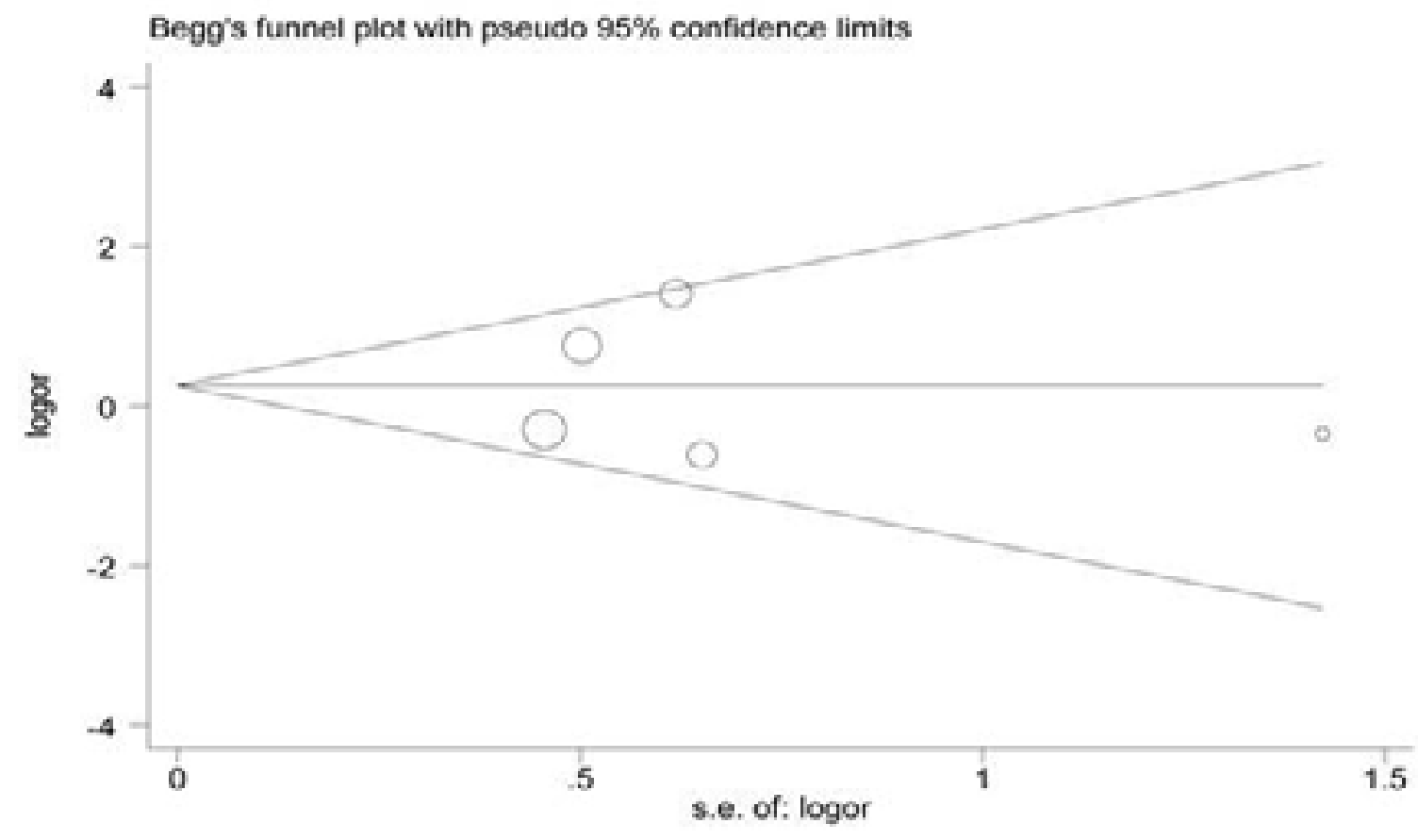

Figure 3. Funnel plot of IL-10 gene -819C/T polymorphism and susceptibility of IBD(Begg's test).

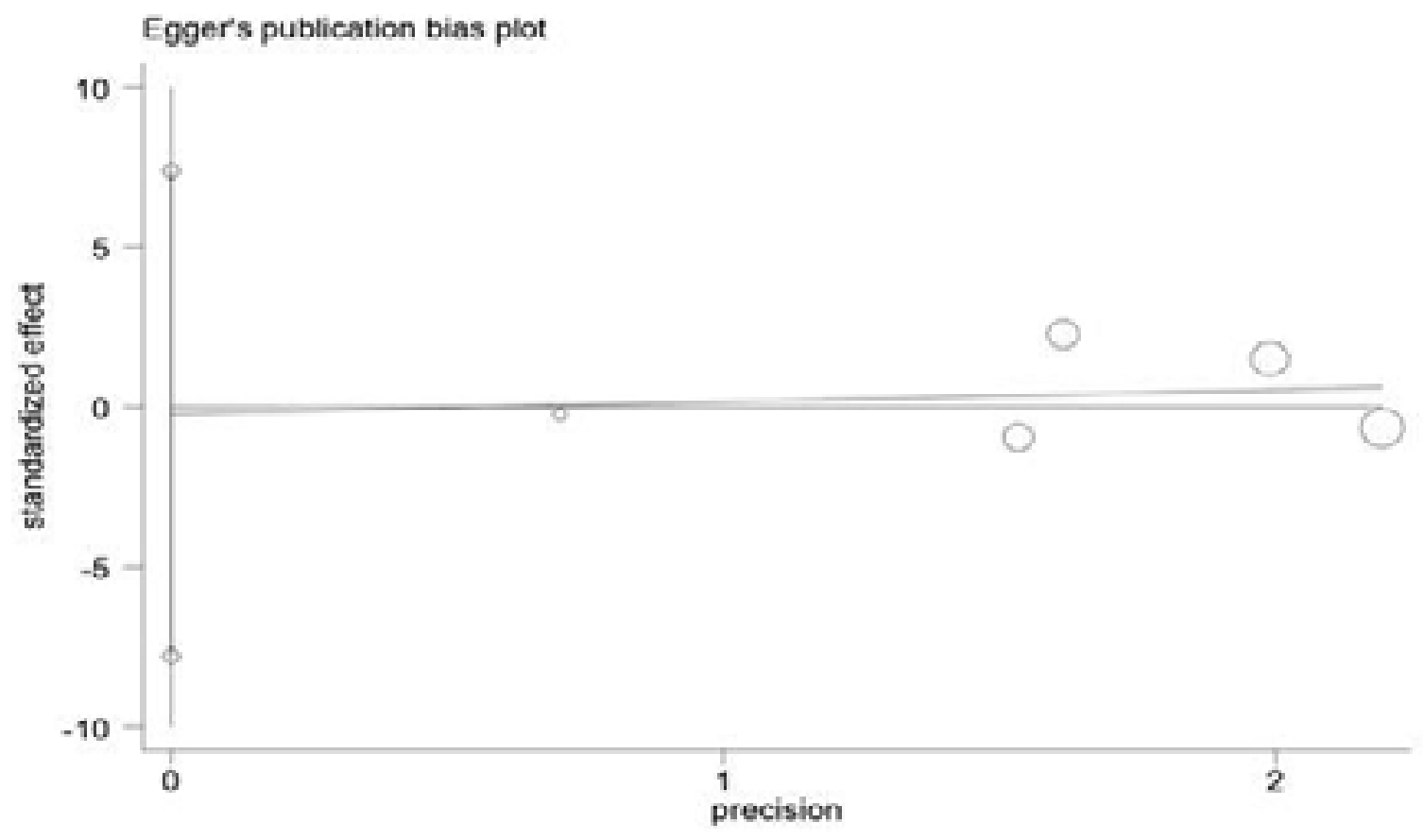

Figure 4. Funnel plot of IL-10 gene -819C/T polymorphism and susceptibility of IBD(Egger regression asymmetry test). 


\section{Discussion}

IBD is characterized by immunologically-mediated chronic and idiopathic inflammatory conditions of the gastrointestinal tract. The cytokine IL-10 suppresses the expression of Th1-derived cytokines and plays as an important immune regulator in the intestinal tract ${ }^{22}$. Cellular gene therapy remains highly investigational, difficult, and expensive $e^{23}$. However the early results are promising. Lactococcus lactis is a non-pathogenic, non-invasive, non-colonizing Gram-positive bacterium, mainly used to produce fermented foods ${ }^{24}$.Steidler et al constructed recombinant lactococcus lactis strains for secretion of biologically active murine IL-10.Using mouse models, they showed that Intragastric administration of IL-10-secreting Lactococcus lactis caused a 50\% reduction in colitis treated with dextran sulfate sodium and prevented the onset of colitis ${ }^{25}$.The recent years have brought much progress regarding the genetics in IBD and the number of confirmed IBD-associated loci and genes have risen dramatically. And some studies suggested that the IL10 gene $-819 \mathrm{C} / \mathrm{T}$ polymorphism is associated with IBD susceptibility, but the results were inconsistent. These inconsistent results could be due to a slight effect of the polymorphism on IBD risk or the relatively low statistical power of published studies. For this reason, a metaanalysis approach was needed to provide a quantitatively assessment of the different results.

The present meta-analysis, which included 1890 cases and 2929 controls from 7 case-control studies, explored the relationship between the $-819 \mathrm{C} / \mathrm{T}$ polymorphism in the IL-10 gene and IBD risk. Overall, the subjects and controls were matched in age and gender and all studies were consistent with HWE in control groups. In the overall comparison of pooled ORs, the meta-analysis results showed no relationship of the IL-10 gene $-819 \mathrm{C} / \mathrm{T}$ polymorphism and the susceptibility to IBD. Subgroup analyses were performed according to ethnicity, showed no correlation of the polymorphism with IBD risk both in Asians and Caucasians. However, there was only one study with Asian subjects, so additional studies that focus on Asians should be considered in future analysis. In the subgroup analysis stratified by IBD type, a significant association was found for $\mathrm{CD}$. The mechanism underlying this association is still unclear. This polymorphism might be affected via gene-gene and gene-environment interactions. The IL10 promoter polymorphisms G-1082A, C-
819T and C-592A have been most extensively studied. They are in tight linkage disequilibrium ${ }^{26}$. There have been reports that G-1082A,-819C/T and C-592A polymorphisms can synergistically increased the risk of $\mathrm{IBD}^{19}$. Interaction between other risk factors and the $-819 \mathrm{C} / \mathrm{T}$ polymorphism in relation to IBD should be a focus of future studies.

There are several limitations in our study, which may affect our conclusions. First, we only included the data from published articles in our analyses, and new data from not yet published studies may alter our findings. Second, we only included the articles written in English, which may exclude some relevant articles. Additionally, some studies lacked original data and this limited our evaluation of potential interactions among gene-gene and gene-environment contributions.

\section{Conclusion}

To the best of our knowledge, this is the first meta-analysis evaluating the association between the $-819 \mathrm{C} / \mathrm{T}$ polymorphism in IL-10 gene and the risk of IBD.Ourresults suggest that the IL-10 gene $-819 \mathrm{C} / \mathrm{T}$ polymorphism may be involved with the susceptibility of CD.Further studies should be performed to validate these results.

\section{Conflict of interest}

None.

\section{References}

1. Molodecky NA, Soon IS, Rabi DM, et al. Increasing incidence and prevalence of the inflammatory bowel diseases with time, based on systematic review. Gastroenterology 2012;142:46-54.

2. Xavier RJ, Podolsky DK.Unravelling the pathogenesis of inflammatory bowel disease. Nature 2007;448:427-434. 3. Zhang H,Ma L,Dong LQ, Shu C,Xu JL.Association of the macrophage migration inhibitory factor gene-$173 \mathrm{G} / \mathrm{C}$ polymorphism with inflammatory bowel disease: a meta-analysis of 4296 subjects. Gene 2013;526:228-231. 4. Lee YH, Kim JH, Seo YH, Choi SJ, Ji JD, Song GG.CTLA-4 polymorphisms and susceptibility to inflammatory bowel disease: a meta-analysis. Hum Immunol 2014;75:414-421.

5. Moore KW, de Waal Malefyt R, Coffman RL, O'Garra A. Interleukin-10 and the interleukin-10 receptor. Annu Rev Immunol 2001;19:683-765. 
6. Celik Y, Dagli U, Kiliç MY, et al.Cytokine gene polymorphisms in Turkish patients with inflammatory bowel disease. Scand J Gastroenterol 2006;41:559-565.

7. Kuhn R,Lohler J,Rennick D, Rajewsky K,Muller W. Interleukin-10-deficient mice develop chronic enterocolitis. Cell 1993;75:263-274.

8. Menegat JS,Lira-Junior R,Siqueira MA,et al.Cytokine expression in gingival and intestinal tissues of patients with periodontitis and inflammatory bowel disease: An exploratory study. Arch Oral Biol 2016;66:141-146.

9. Yin Q,Zhai Q,Wang D,et al.Investigation on the association between inerleukin-10 -592C/A, 819C/T and $-1082 \mathrm{~A} / \mathrm{G}$ gene polymorphisms and development of diabetic nephrophathy. Int J Clin ExpPathol 2015;8:1521615221.

10. Eskdale J, Gallagher G, Verweij CL,et al.Interleukin 10 secretion in relation to human IL-10 locus haplotypes. Proc Natl Acad Sci U S A 1998;95:9465-9470.

11. Zhu H, Lei X, Liu Q, Wang Y.Interleukin-10-1082A/G polymorphism and inflammatory bowel disease susceptibility: a meta-analysis based on 17,585 subjects. Cytokine 2013;61:146-153.

12. Lee YH,Choi SJ,Ji JD,et al.Associations between the angiotensin-converting enzyme insertion/deletion polymorphism and susceptibility to vasculitis: a meta-analysis. J Renin Angiotensin Aldosterone Syst 2012;13:196-201.

13. Egger M, Smith GD, Phillips AN.Meta-analysis: principles and procedures. BMJ 1997;315: 1533-1537.

14. Dupont WD and Plummer WD.Power and Sample Size Calculations for Studies Involving Linear Regression. Controlled Clinical Trials 1998; 19:589-601.

15. Ahirwar DK,Kesarwani P,Singh R,Ghoshal UC,Mittal RD.Role of tumor necrosis factor-alpha (C-863A) polymorphism in pathogenesis of inflammatory bowel disease in Northern India. J Gastrointest Cancer 2012;43:196-204. 16. Amre DK,Mack DR,Morgan K,et al.The polymorphism rs3024505 proximal to IL-10 is associated with risk of ulcerative colitis and Crohns disease in a Danish casecontrol study. BMC Med Genet 2010;11:82.
17.Fernandez L,Martinez A,Mendoza JL,et al.Interleukin-10 polymorphisms in Spanish patients with IBD. Inflamm Bowel Dis 2005;11:739-743.

18. Sanchez R,Levy E,Costea F,Sinnett D.IL-10 and TNF-alpha promoter haplotypes are associated with childhood Crohn's disease location.World J Gastroenterol 2009;15:3776-3782.

19. Wang AH, Lam WJ,Han DY, et al.The effect of IL10 genetic variation and interleukin 10 serum levels on Crohn's disease susceptibility in a New Zealand population. Hum Immunol 2011;72:431-435.

20. Tedde A,Laura Putignano A,Bagnoli S,et al.Interleukin-10 promoter polymorphisms influence susceptibility to ulcerative colitis in a gender-specific manner. Scand J Gastroenterol 2008;43:712-718.

21. Andersen V, Ernst A, Christensen J,et al.The polymorphism rs3024505 proximal to IL-10 is associated with risk of ulcerative colitis and Crohns disease in a Danish case-control study. BMC Med Genet. 2010;11:82.

22. Haub S,Ritze Y,Bergheim I,Pabst O,Gershon MD,Bischoff SC.Enhancement of intestinal inflammation in mice lacking interleukin-10 by deletion of the serotonin reuptake transporter. Neurogastroenterol Motil 2010;22:826-834.

23. Jafarlou M, Baradaran B, Saedi TA, et al.An overview of the history, applications, advantages, disadvantages and prospects of gene therapy. J Biol Regul Homeost Agents. 2016;30:315-321.

24. Zhang J, Caiyin Q, Feng W, et al.Enhancenisin yield via improving acid-tolerant capability of Lactococcus lactis F44. Sci Rep. 2016;6:27973.

25. Steidler L, Hans W, Schotte L, et al.Treatment of murine colitis by Lactococcus lactis secreting interleukin-10. Science 2000;289:1352-1355.

26. Turner DM,Williams DM,Sankaran D,Lazarus M,Sinnott PJ, Hutchinson IV.An investigation of polymorphism in the interleukin-10 gene promoter. Eur J Immunogenet 1997;24:1-8. 